shore. The theory suggests a definit 9 two to one relationship between the periods of the sea-waves and microseisms, which has been confirmed by observations. Further, by submitting simultaneous records of waves and microseisms to frequency analysis, it has been thought safe to conclude that a depression moving rapidly over deep water north of the Azores caused microseisms at Kew. Microseisms on Kew seismograms can be detected some thirty hours before the swell from a distant storm reaches the coast.

ERnest Tillotson

$$
\text { ph }
$$

\section{MAGNETIC AMPLIFIERS}

$\mathrm{T}$ HE thermionic valve amplifier is so universal in its applicat nn al even the existence of other means of amplfying ends to be overlooked. Two papers read receftly before the Institution of Electrical Engineers record developments in magnetic amblip rs, and indicate the field of application within which such amplifiers possess advantages. Thespe porsers, "Magnetic Amplifiers", by A. G. Mibles, as "A Theoretical and Experimental Study of the Series-Connected Magnetic Amplifier", by H. M. Gale and P. D. Atkinson, were presented on December 2, 1948.

Essentially the principle of the magnetic amplifier is that of controlling the current in an A.c. circuit by varying, by means of an auxiliary D.C. circuit, the impedance of an iron-cored reactor in series with the load. The D.c. circuit thus effects its control by producing magnetic saturation of the reactor core. This principle has been known and has been applied for many years, indeed since the period of the First World War; but it was not until high-permeability nickel-iron alloys and metal rectifiers became available that rapid development of the magnetic amplifier for a wide range of applications took place.

The basic circuit arrangements of magnetic amplifiers have now assumed fairly well established forms, and the present papers give a systematic theoretical treatment and design procedure for the standard circuits. As a rule the magnetic amplifier operates as a D.C. amplifier in the sense that the input or controlling current is a small direct current, and the output is again a direct current produced by the rectification of the alternating current passed by two reactors, the reactance of which is controlled by the input. A simple, single-stage magnetic amplifier employing high-permeability cores might give a power-gain of the order of 10 to 20. This gain may be very greatly increased, however, by the use of positive feed-back. Feed-back is applied by circulating the direct output current through an additional winding on the cores. If the magnetic effect of this feed-back winding is in such a direction as to reinforce that of the input current, there is partial self-excitation which increases the ratio of output current to input current. The effects of feed-back are closely analogous to those obtained with thermionic amplifiers, and excessive positive feed-back will give rise to instability. Positive feed-back is commonly utilized to obtain power gains per stage of the order of 2,000 . Without feed-back a magnetic amplifier does not discriminate between positive and negative input signals; but with the application of feed-back, reversal of the polarizing flux changes the feed-back from positive to negative, and discrimination results. Magnetic amplifiers commonly operate with input powers of the order of a microwatt, and it is stated in one of the papers that $10^{-8}$ watt may be regarded as the lower usable limit of input power.

Perhaps the most significant difference between the behaviour of the magnetic amplifier and that of the thermionic amplifier lies in the time delay of the response of the magnetic amplifier to a sudden change of input. The build-up of the steady state following a sudden alteration of input is approximately exponential, and the response-time of magnetic amplifiers is usually expressed as the time-constant of an approximately equivalent exponential rise. This time delay, which is practically inversely proportional to the frequency of the A.c. supply and increases in proportion to the stage amplification, is one of the important limiting factors in the application of magnetic amplifiers. In order to obtain a high ratio of amplification to time-constant it is desirable to connect a number of stages in cascade, since the overall amplification is the product of the amplifications of the individual stages, whereas the total time-constant is, very roughly, the sum of the time-constants of the stages.

It is interesting to note that in the two papers the theoretical analysis proceeds along quite different lines, and different approximate-design techniques are developed. It is pointed out that a magnetic amplifier to control a given power output is ordinarily considerably larger than the corresponding power transformer, and supply frequencies in the range 400-1,600 c. s. are commonly employed in order to reduce the size of the equipment. The equivalent exponential delay of an amplifier is stated to correspond to a time-constant of the order of 2-100 cycles of the supply frequency. JAMES GREIG

\section{$I_{\mathrm{d}}^{\mathrm{N}}$}

\section{RECRUITMENT AND TRAINING FOR THE IRON AND STEEL} INDUSTRY order that continuous and rapid technical developmans in the iron and steel industry shall not outruiline capabilities of the men who will be required.to operate the processes involved, the Brish Iron and Steel Federation has recently pre atred recruitment and training schemes to benefit the industry as a whole. Based on the experience gained by various firms who have already developed training programmes of a far-reaching character, the Recruitment and Training Committee of the Federation has introduced a sample training scheme which has been circulated to all member firms. In order that the scheme should be fully discussed and improved, a Conference was held at Ashorne Hill, Leamington, on January 14-16, 1949, under the chairmanship of Mr. Gerald Steel, joint managing director of the United Steel Companies. The Conference was attended by representatives of member firms from all parts of Britain, and included production managers as well as personnel officers of various grades.

Pointing out that the number of youths in industry between the ages of 14-18 years had fallen from $3 \frac{1}{4}$ millions in 1938 to $2 \frac{1}{2}$ millions in 1947 , Mr. A. Goodram, of Samuel Fox and Co., Ltd., discussed the training of the junior operative both from the economic and social points of view. In his own Company the 